\title{
Reputations in mixed-role markets: a theory and an experimental test*
}

\author{
Judith Kas \\ Rense Corten \\ Arnout van de Rijt \\ Department of Sociology/ICS, Utrecht University
}

*Correspondence concerning this article should be addressed to Judith Kas, who is at the

Department of Sociology, Utrecht University, Padualaan 14, 3584 CH Utrecht, The

Netherlands. E-mail: j.kas@uu.nl.

Support for this research was provided by the Netherlands Organization for Scientific

Research, grant 452-16-002. The authors thank Joris Broere, Vincent Buskens, Joyce Delnoij,

Nikki van Gerwen, Rita Jiao, Hendrik Nunner, Wojtek Przepiorka, Werner Raub, Jaap van

Slageren and Eva Vriens for comments that greatly improved the manuscript and for their assistance in running the experiment.

A reviewed and revised version of this manuscript has been published in Social Science Research: https://doi.org/10.1016/j.ssresearch.2019.102366. 


\title{
REPUTATIONS IN MIXED-ROLE MARKETS: A THEORY AND AN EXPERIMENTAL TEST
}

\begin{abstract}
The traditional understanding of reputation systems is that they secure trust between strangers by publicly calling out cheaters. In modern, online markets, it is increasingly common for providers of a good to also act as consumers, and vice versa. We argue that in such mixed-role markets, reputation systems serve a second important function: They allow providers who lend out their possessions (such as their house, car or tools) to earn reputational credits that can be spent in future exchanges when in their role as consumer, especially when they do not receive a monetary compensation. In an experiment that introduces a new game, "the Lending Game", we show that, consistent with our argument, information on past lending leads subjects to lend to those who have themselves lent before, increasing overall lending. However, when provision is financially compensated, and thus no longer a generous act, this reputational mechanism ceases to work.
\end{abstract}

Keywords: Reputation systems, Trust, Two-sided markets, Experiment 


\section{REPUTATIONS IN MIXED-ROLE MARKETS: A THEORY AND AN EXPERIMENTAL TEST}

The Internet opens up the possibility for interaction and economic exchange between strangers all around the world. Online exchange is characterized by anonymity, and strangers often interact without the prospect of future interactions (Kuwabara, 2015; Parigi, Santana, \& Cook, 2017). Individuals may benefit from exchange mediated by online environments, but with limited information and limited control over the decisions made by others, there is always the threat that one's trust is abused. A seller may not deliver after payment, a buyer may not pay after delivery, and a borrower may not return a lent good in time or intact.

Reputation systems are widely used to overcome trust problems in exchange between strangers (Cook, 2005). These systems inform individuals about past behavior of potential exchange partners. The positive effect on trust of the classic, single-role reputation system in which one actor only acts in one role (e.g. either as provider or as user) is well established in the existing literature (Boero, Bravo, Castellani, \& Squazzoni, 2009; Bolton, Katok, \& Ockenfels, 2004; Charness, Du, \& Yang, 2011; Duffy, Xie, \& Lee, 2013; Fehrler \& Przepiorka, 2013). However, individuals increasingly act in multiple roles in modern-day exchange, acting as supplier of a good or service in one transaction while being on the receiving end in another (Cova, Dalli, \& Zwick, 2011; Ritzer \& Jurgenson, 2010). For example, consumer-to-consumer marketplace eBay allows individuals to both buy and sell, peer-to-peer hospitality services Couchsurfing and Airbnb allow home owners to open up their houses to strangers, while staying at others' homes when traveling themselves (Lauterbach, Truong, Shah, \& Adamic, 2009), and crowdfunding platform Kickstarter allows individuals to raise funds for their own projects and to fund projects of others.

In such cases where the lines between actors in different roles are blurred, a new type of reputation system emerges. This mixed-role reputation system allows individuals to not only 
examine another individual's past behavior in his or her current role, but also past behavior in other roles. For example, Couchsurfing hosts cannot only view ratings potential guests received from other hosts, but also reviews these potential guests received from other guests when they were host themselves.

Mainstream theory of reputation systems suggests this information is, at best, of secondary importance, because the best indication of whether someone can be trusted is that they have honored trust in the past, not whether they themselves have trusted other people (e.g., Buskens, 2002). Yet anecdotal evidence suggests that this extra information is actually a very important criterion for platform users when making decisions. For example, on online forums Couchsurfing hosts said: 'One thing that may help is to host, if you're not already. That's the first thing I look for whenever I get a request. If they've hosted before and the review was positive, I almost always accept' [them as a guest]' (Reddit, 2015) and 'One thing I have considered is only hosting people who are themselves active hosts' (Quora, 2016). Research among Couchsurfing hosts suggests that hosts care about potential guests' past hosting behavior and that it is considered a general principle that one should alternate between surfing and hosting (Geiger, 2015; Geiger \& Germelmann, 2015). On Couchsurfing, the number of times a member has surfed and hosted are highly correlated (Lauterbach et al., 2009), consistent with the notion that Couchsurfing users care about a balance between hosting and surfing experiences.

Not only free platforms such as Couchsurfing use this mixed-role reputation system. Car sharing platform Turo allows car owners to rent out their car to others and shows both reviews from travelers and reviews from car owners in the user profiles of car owners. The distinction between monetized exchange that includes financial remuneration (selling, renting etc.) and non-monetized, free exchange (e.g. lending) is relevant here, because the motivation of the users to participate in exchange is different. In the case of monetized exchange, individuals may 
decide to take the risk because they believe the monetary benefits outweigh the risk. In free exchange, there are no direct material benefits related to placing trust, so other motivations may play a larger role. Placement of trust, i.e., lending something valuable without financial compensation, is then easily viewed as an act of generosity or kindness. We argue that this difference between paid and free platforms not only leads to an overall difference in trust levels, but also to a difference in the effectiveness of implementing a mixed-role reputation system.

Thus, although mixed-role reputation systems are increasingly common, especially in online exchange, existing theories about single-role reputation systems do not provide an explanation for why and when this extra reputation information affects trust. In the current paper we develop a theoretical framework explaining why information about the other role is important when making decisions and how that affects trust at the platform level. We argue that the effect of mixed-role reputation systems is stronger for platforms where goods or services are provided for free than on platforms where users have to pay. We perform a test of the theory in a controlled laboratory experiment in which we compare the effect of the single-role reputation system with the mixed-role reputation system in both paid and free exchange.

\section{THEORY}

In the scenarios we study, individuals alternate between the role of provider and user. We first discuss, as a baseline, how the often-studied single-role reputation system, in which otherrole reputational information is absent, functions in paid exchange, using the example of car sharing platform Turo.

\subsection{Paid exchange and single-role reputation systems}

The classic understanding of how reputation systems help achieve trust in markets can be well explained using the analytical tools of game theory (Kreps, 1996). The situation in the 
direct (paid) exchange is typically represented as a Trust Game (Coleman, 1990; Dasgupta, 1988; Kreps, 1996) in the left panel Figure 1. In this figure, $T, R, P$ and $S$ represent the material payoffs of the actors. In the Trust Game, a "trustor" first chooses whether to place trust or not. If the trustor decides not to place trust, the game is over and both players receive payoff $P_{i}$. For example, if a car owner on Turo decides not to rent out the car, the user cannot make use of the car and the car owner will not receive the payment from the guest. If the trustor decides to place trust (i.e., decides to rent out the car), the "trustee" (the car user) can choose to honor trust (i.e., return the good in a good state or abuse the trustor's trust (i.e., not return the good, or not return the good in a good state) $)^{1}$. If the user honors trust, both car owner and user are better off than when the request is not accepted, because the car owner receives the payment and the user can drive a car. In that case, both players receive a payoff of $R_{i}$ that is higher than the payoff $P_{i}$ that they would receive if no trust was placed. If the user however decides to use the car in a way that induces costs for the owner, e.g. by smoking or by using the car for moving houses, the user benefits more than when he or she would have refrained from smoking or using the car for moving, while the host would have been better off when the user would not have rented the car at all. In the trust game, this incentive structure is represented by the car owner receiving a payoff of $S_{1}$ that is smaller than $P_{1}$ and the user receives a payoff $T_{2}$ that is larger than $R_{2} \cdot{ }^{2,3} \mathrm{~A}$ numerical example of the Trust Game is shown in the right panel of Figure 1.
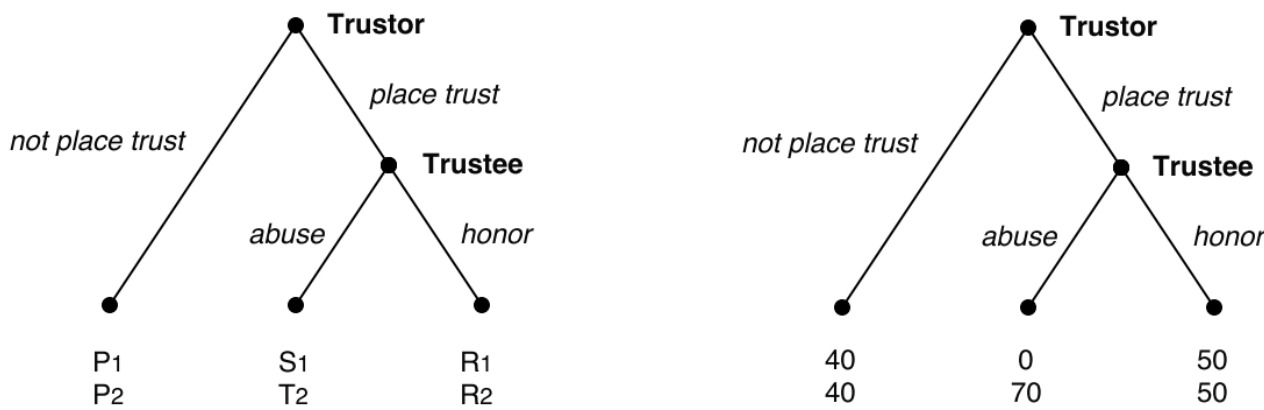

Figure 1: left panel: Trust Game, where $\mathrm{R}_{1}>\mathrm{P}_{1}>\mathrm{S}_{1}, \mathrm{~T}_{2}>\mathrm{R}_{2}>\mathrm{P}_{2}$ and $\mathrm{P}_{1}+\mathrm{P}_{2}>\mathrm{S}_{1}+\mathrm{T}_{2}$. Right panel: numerical example used in the current experiment. 
Under the standard game-theoretic assumptions of rationality and selfishness, trustors in the Trust Game would anticipate that trustees will always abuse trust when they get the chance. Therefore, trustors would always refrain from placing trust and there would be no interactions on Airbnb, Turo, Couchsurfing, Peerby and other platforms. Reputation systems are often mentioned as a very effective means for solving this problem if the trustee expects to face other trustors in the future. These systems collect, aggregate and distribute feedback about trustees' past decisions to trustors (Resnick, Kuwabara, Zeckhauser, \& Friedman, 2000) ${ }^{4}$. Extensive research shows that single-role reputation systems have a strong, positive impact on trust in the Trust Game (Boero et al., 2009; Bolton et al., 2004; Charness et al., 2011; Duffy et al., 2013; Fehrler \& Przepiorka, 2013) and that general exchange systems can emerge when information about other's past behavior is available (Takahashi, 2000). Single-role reputation systems are thought to affect trust through three mechanisms: learning, control and indirect reciprocity.

\subsubsection{Learning.}

Trustees will differ in the extent to which they are willing to honor trust, but without any information about the incentives of trustees, trustors do not know which trustees will probably honor trust and which will likely not (Macy \& Skvoretz, 1998). A trustee's reputation may help here. Trustors may use the available information on past trustee behavior to update their beliefs about the trustee's motivations (Buskens, 2003; Cook, Hardin, \& Levi, 2005; Weigelt \& Camerer, 1988). The more a trustee has honored trust in the past, the more likely he has only weak incentives for abusing trust and the higher the likelihood that he will honor trust in the future and vice versa. Consequently, when a single-role reputation system is in place, broadcasting trustees' reputations to trustors, trustors place more trust in trustees who have honored more trust in the past.

A large number of studies on reputation systems show that trustors indeed use same-role reputation information as predicted: the more trust a trustee has honored in the past, the higher 
the probability that a trustor places trust (Buskens, Raub, \& van der Veer, 2010; Charness et al., 2011; Duffy et al., 2013), and the higher the prices they can charge (Ba \& Pavlou, 2002; Dewally \& Ederington, 2006; Dewan, Hsu, Dewanw, Hsuz, \& Rogers, 2004; Diekmann, Jann, Przepiorka, \& Wehrli, 2014; Resnick, Zeckhauser, Swanson, \& Lockwood, 2006; Snijders \& Zijdeman, 2004; see also the literature review in Diekmann et al., 2014)

\subsubsection{Indirect reciprocity.}

A second mechanism through which reputation information affects decision making is indirect reciprocity. Reciprocity is the conditional behavior to return helpful and harmful acts in kind, even when this is costly for the reciprocator (Stanca, 2009). In the case of online platforms, individuals often act only a single time with another buyer or seller, so it is often not possible to directly reciprocate a favor (Cabral, Hortacsu, \& Hortaçsu, 2010), but reciprocity may also be indirect (Molm, Schaefer, \& Collett, 2007). In the Trust Game with single-role reputation, rational trustors with a preference for reciprocity could base their decision to place trust or not on the trustee's reputation: a trustee who has honored a lot of trust in the past, may be perceived as deserving more trust than an untrustworthy trustee. Likewise, trustors might want to punish by not placing trust in trustees who have abused trust in the past.

Evidence of such reciprocal behavior comes, for example, from public goods experiments where people were willing to punish free-riders, even when punishing is costly (Fehr \& Gächter, 2000; Kuwabara \& Yu, 2017). The meta-analysis by Balliet, Mulder and Van Lange (2011) shows that giving individuals the possibility to punish and reward others has a positive effect on overall cooperation.

The indirect reciprocity mechanism, like the learning mechanism, predicts that trustees with better reputations are trusted more. The evidence cited above in support of the learning mechanism is therefore also compatible with the indirect reciprocity mechanism. 


\subsubsection{Control.}

The third mechanism is about the control the reputation system gives trustors over the longterm incentives of trustees to honor or abuse trust (Buskens \& Raub, 2002). If trustors in the game with single-role reputation only place trust in trustees who have proven to be trustworthy in the past (i.e., who have not abused trust in the past), opportunistic trustees may be motivated to keep up the image that they are trustworthy (Robbins, 2016). If trustors anticipate this line of thought of the trustees, they may be stimulated to place more trust, because they will realize that trustees are less likely to abuse trust (Buskens, 2003; Weigelt \& Camerer, 1988). The control mechanism predicts that when a reputation system is in place trustors are more willing to trust even trustees lacking any reputation. Reputation systems may also provide an example of what is considered to be acceptable behavior to individuals and pressure them to live up to these norms (Norbutas \& Corten, 2018; Tsvetkova \& Macy, 2014). The prediction that individuals anticipate reputation effects is borne out in numerous studies (Benard, 2013; Buskens \& Raub, 2002; Buskens \& Weesie, 2000; Charness et al., 2011; Cheshire, 2007; Kroher \& Wolbring, 2015; Rooks, Raub, \& Tazelaar, 2006).

\subsection{Free exchange and mixed-role reputation systems}

In paid exchange, a single-role reputation system allows trustors to learn about the preferences of trustees and act accordingly. When trustees realize that their decisions affect their odds of being trusted again in the future, they may strategically invest in their reputation by honoring trust. These arguments explaining the effectiveness of single-role reputation systems in paid exchange rely on the assumption that providers want to avoid negative payoffs and have an incentive to increase their payoff. However, this reasoning does not lead to the same predictions for free exchange (or generalized exchange systems). Since providers in this case do not receive financial remuneration, they cannot gain anything by lending out their 
goods, so, under the standard assumptions of rationality and selfishness, they are not expected to ever do so, even when they are confident that the user would act honorably.

Yet there are numerous examples of free platforms that are functioning well and that attract both users and providers. Why would providers suffer a sure loss if they do not get anything in return? Of course, the non-material rewards, other-regarding preferences and social aspects of these exchanges assumed away in narrowly formulated game-theoretic models may well be part of the explanation (e.g. Grybaitė \& Stankevičienè, 2016; Hamari, Sjöklint, \& Ukkonen, 2015; Hars \& Ou, 2002). Altruists just generously share their property with others, at the risk of being taken advantage of. Here we propose that in addition to such sheer goodness, mixed-role reputation systems play an important role in facilitating free exchange. Namely, they do not only provide information on the provider's behavior in the provider role, but also on that provider's behavior in the user role. This extension of the classic, single-role reputation system allows providers to get something in return for their generosity, explaining why even purely egoistic providers would lend out their goods.

\subsubsection{The Lending Game.}

To characterize the indirect (free) exchange situation, we introduce a new game, the "Lending Game" (Figure 2). In the Lending Game, just as in the Trust Game, a trustor decides whether to place trust or not. For example, a Peerby user can decide to lend out a good for free to a neighbor or not. Lending out goods is beneficial to the borrower but comes at a small material cost to the owner of the good $^{5}$. The owner needs to spend some time and effort arranging a meeting with the borrower and the owner cannot use the good for the time the user is borrowing it. Even if the borrower honors trust (i.e., returns the good in a good state) the owner faces these small costs, while not getting a material payoff in return. If the borrower abuses trust (i.e., does not return the good, or does not return the good in a good state) the owner 
suffers a considerable material loss. In this situation, the trustor is always worse off when she places trust than when she withholds trust, even when the trustee honors trust $\left(\mathrm{R}_{1}<\mathrm{P}_{1}\right)$.

The unique Nash equilibrium for one-shot play of this game is the same as in the Trust Game: the trustor does not place trust. In contrast to the Trust Game, this equilibrium is Paretooptimal: Neither party could have been better off, without the other being worse off. However, it does not maximize overall welfare, as the borrower (trustee) could have been made a lot happier at a small price to the owner (trustor). This generalized exchange system constitutes a social dilemma, as the best option for the group is at odds with the best outcome for the individual (Kollock, 1999; Yamagishi \& Cook, 1993).
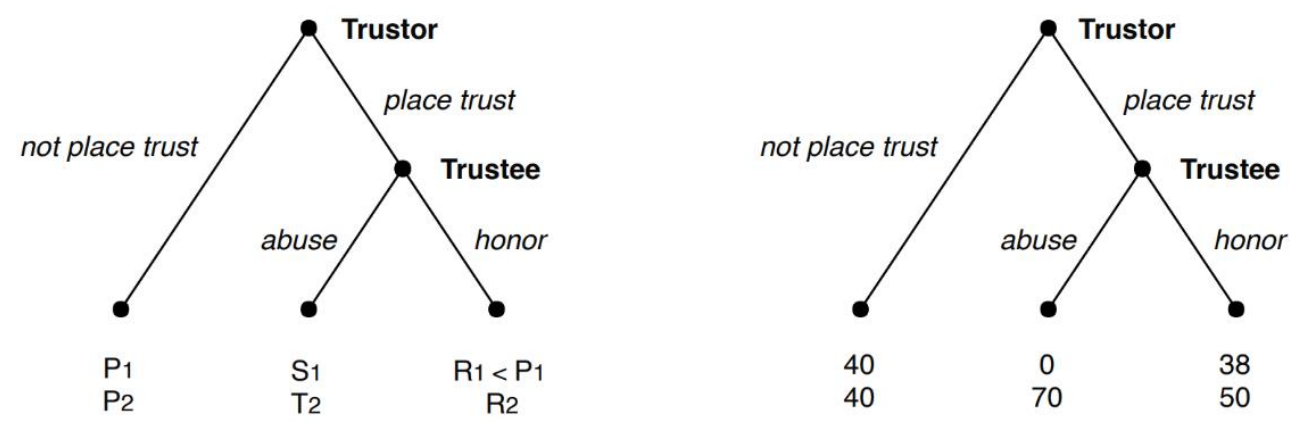

Figure 2: left panel: Lending Game, where $\mathrm{R}_{1}=\mathrm{P}_{1}>\mathrm{S}_{1}, \mathrm{~T}_{2}>\mathrm{R}_{2}>\mathrm{P}_{2}$ and $\mathrm{P}_{1}+\mathrm{P}_{2}>\mathrm{S}_{1}+\mathrm{T}_{2}$. Right panel: numerical example used in the current experiment.

\subsubsection{Learning in the Lending Game.}

Egoistic trustors in free exchange situations with single-role reputation (i.e., trustors who only care about her own payoff and not about the payoff of others) will never place trust, because that always leads to a decrease in their own payoff. More altruistic trustors may be willing to take the loss associated with placing trust when the trustee honors trust. We argue that the decisions individuals make in one role are driven by the same motivations as the decisions that individuals make in the other role in free exchange situations. For example, Peerby users who are more likely to treat someone else's goods well may also be more likely to lend their goods to other people. The rationale behind this assumption is that in free exchange 
both placing trust and honoring trust lead to a decrease in one's own payoffs, while it has a positive effect on the other player's payoff. Therefore, individuals who are more inclined to give up their own payoff for an increase in the payoff of others should be more likely to both place and honor trust, because both behaviors are expected to increase the payoff of the other while they decrease a player's own payoff.

Experimental evidence indeed suggests that when subjects play both roles, behavior in the trustee role is often related to behavior in the trustor role (Charness et al., 2011; Seinen \& Schram, 2006). Other studies have found that an individual's cooperative behavior in one situation is related to that individual's trustworthiness in other situations (Chaudhuri \& Gangadharan, 2007; Fehrler \& Przepiorka, 2013).

Combining these arguments leads to the prediction that the more trust an individual has placed in the past, the more altruistic he or she likely is and the larger the probability that he or she will honor trust in the present. In free exchange with a mixed-role reputation system, trustors may thus learn about a trustee's incentive to honor trust from their past trustor behavior.

In paid exchange the relation between an individual's behavior in the trustor role and the trustee role is much less clear in that situation than when the trustor does not receive money. In paid exchange, the trustor may thus place trust out of direct self-interest as long as her belief that the trustee will honor trust is strong enough. Because there are fewer self-regarding reasons why trustors would place trust in the Lending Game than in the Trust Game, placing trust serves as a stronger, less noisy indicator of a trustee's prosocial preferences in the former.

Hypothesis 1a: The more trust a trustee has placed in the past, the higher the likelihood that the trustee will be trusted. 
Hypothesis 1b: The positive effect of placing trust in the past on receiving trust in the future is stronger in the Lending Game than in the Trust Game.

In a laboratory experiment by Charness, Du, and Yang (2011), trustors used the information they received about the trustees' decision in the other role. This supports hypothesis 1a. However, the trustors in that experiment did not also receive information about the trustee's behavior in the current role, so it is unclear whether trustors would still have used the other-role information had they also been given same-role information.

\subsubsection{Indirect reciprocity in the Lending Game.}

The tendency to reciprocate behavior of strangers is also expected to result in more trust being placed in trustees who have themselves placed trust in the past, if a mixed-role reputation system is in place. Placing trust is a risky and altruistic act in the Lending Game and trustors may want to reward trustees for their past trustful decisions and punish distrustful trustees. This effect is expected to be stronger in the Lending Game than in the Trust Game (hypothesis 1b), because although placing trust is risky in both games, it can be considered a less selfish act in the former, which is thus more deserving of rewards.

The effect of other-role reputation through indirect reciprocity has previously been studied in scenarios outside the realm of trust problems. In the Helping Game or Image Scoring Game a donor can choose to give a gift to a receiver or not, donors were found to give more to receivers who had helped more in the past and helping rates were higher when donors were able to learn about past behavior of receivers than when no reputation system was in place (Bolton, Katok, \& Ockenfels, 2005; Engelmann \& Fischbacher, 2009; Seinen \& Schram, 2006). Other studies have described the emergence and importance of reciprocity in generalized exchange situations in the field, such as the Kula Ring (Malinowski, 1922) and in simulation studies (Takahashi \& Mashima, 2003). 


\subsubsection{Control in the Lending Game.}

A mixed-role reputation system allows players to invest in their reputation by placing more trust. If opportunistic trustors believe that their trust will be reciprocated in the future if they place more trust in the present, they may place trust with the intention to evoke this reciprocity. Consequently, when information about past trustor behavior is public, trustors will be more inclined to place trust, even when they are not sure about the motives of the trustee.

We expect a difference in the amount of strategic reputation building between a situation with a single-role reputation system and a situation with a mixed-role reputation system. Unlike a situation with a single-role reputation system, the control effect works both directly and through trustee-behavior in the mixed-role reputation: trustors may place more trust not only because they believe that trustees refrain from abusing trust because it is detrimental to their reputation but also because they expect to be rewarded for it by other trustors in the future. Previous research on control mechanisms has shown that trustees may indeed seek to increase the probability of receiving trust by making generous choices in other, unrelated situations (Elfenbein, Fisman, \& Mcmanus, 2012; Fehrler \& Przepiorka, 2013).

Combining the various mechanisms, we expect that mixed-role reputation systems allow individuals to build a reputation not only for honoring trust but also for being generous and thus deserving of others' generosity. Mixed-role reputation systems let trustors learn more about trustees' preferences and also reward or punish trustees for their past behavior not only as former trustee but also as former trustor.

Hypothesis 2a: Both in the Trust Game and in the Lending Game, more trust is placed under a mixed-role reputation system than under a single-role reputation system. 
In the Lending Game, in which there is no material incentive to place trust other than building up credit that may or may not be repaid one day, a history of placing trust in others is a particularly strong signal of altruism and an act of generosity. The increased uncertainty in generalized exchange systems (i.e., the Lending Game) makes being generous more risky than in direct exchange systems (i.e., the Trust Game) (Molm, 2010; Molm, Schaefer, \& Collett, 2009). Past trustful behavior can therefore be considered a stronger signal of future trustworthiness in the Lending Game than in the Trust Game, and mixed-role reputation systems should increase trust levels more in the former than in the latter.

Hypothesis 2b: Mixed-role reputation systems increase trust placement more in the Lending Game than in the Trust Game.

We do not have a strong expectation regarding the effect of mixed-role reputation systems on trustee behavior, as the expectations from a learning argument and a control argument contradict. Following learning arguments, we would expect an increase in trustworthiness with the introduction of a mixed-role reputation system, while control arguments predict a decrease in trustworthiness.

\section{EXPERIMENT}

The experiment was conducted at [BLINDED FOR REVIEW] between November $29^{\text {th }}$ 2017 and December $12^{\text {th }} 2017$. Four pilot sessions were organized on November 15 and 16 , 2017. Using a laboratory experiment allows us to study reputation in isolation and to make inferences about causality. Subjects were students of [BLINDED FOR REVIEW] and were recruited using the internet recruitment system ORSEE (Greiner, 2015). All laboratory sessions were computerized using Z-tree 3.6.7 (Fischbacher, 2007). The subjects received printed 
instructions in English. There were 228 subjects in total, divided over twelve sessions. Each session consisted of two or three matching groups of eight, ten or twelve subjects each. After reading the instructions and before the start of the experiment, subjects had to answer some questions to test their comprehension of the instructions. At the end of the session subjects completed a short survey that included demographic questions, a question on their experience with game theory and questions on subjects' motivations and beliefs about other participants.

Each session took about 60 minutes (including the time for reading instructions). The average payment was 8.89 euro (100 points were equivalent to 0.60 euro). There were 156 (68.4\%) subjects identifying as female, 69 (30.3\%) identifying as male, and one subject indicating 'other gender'. Age ranged from 18 to 66 and was on average $23.4(\mathrm{SD}=6.0)$.

The participants were informed that the session consisted of 36 rounds. At the beginning of each round, half of the participants were assigned the role of trustor (role A) and half of the participants were assigned the role of trustee (role B). We arranged the draws such that each person was a trustor six times and a trustee six times in each block of 12 rounds (cf. Charness et al., 2011) ${ }^{6}$. At the end of the session, each subject had played 18 times in the trustor role and 18 times in the trustee role. This procedure ensured that the number of times all subjects acted in the roles of trustor and trustee did not vary too much at any point in time, but at the same time that subjects did not know for sure what role they would play in the next round. The participants were randomly and anonymously matched in pairs within their matching group at the beginning of each round. They knew they were divided in two or three different groups (depending on the number of participants in the session) and they knew they only interacted with the people in their group. No communication between the participants was allowed during the experiment. 
At the end of the round, after the players made their decisions, both players were informed about their own choice and payoff of that round, the choice and payoff of their partner in that round and their own total payoff.

The experiment had a 2 (Trust Game versus Lending Game) by 2 (single-role reputation versus mixed-role reputation) design. There were three sessions in each of the conditions, for a total of 12 sessions. In the Trust Game, the trustor chose at the start of each round between RIGHT (not place trust) and DOWN (place trust). If the trustor chose RIGHT, the round was over and both players received a payoff of 40 . If the trustor chose DOWN, the trustee had to make a choice between RIGHT (abuse trust) and DOWN (honor trust). If trustee chose to abuse trust, the trustor received 0 and the trustee received 70 . If the trustee chose to honor trust, both players received a payoff of 50. The only difference between the Lending Game and the Trust Game was the payoff of the trustor if the trustee decided to honor trust. Instead of 50, the trustor received a payoff of 38 in the Lending Game when trust was honored. Appendix A contains the instructions for the participants in the different conditions.

In the single-role reputation conditions, before making a choice, the trustor was informed about the total number of decisions the trustee made in the trustee role and the number of times the trustee chose to honor trust in the past. In the mixed-role reputation condition, the trustor was also informed about the number of past decisions trustee had made as trustor and the number of times he had placed trust. Note that trustees received no information about the trustor's past behavior in any of the conditions.

\section{ANALYSIS AND RESULTS}

\subsection{Analytical strategy}

To test hypothesis 1a, we performed separate multilevel logistic regressions for the four conditions with the decision of the trustor (place trust or not) as the dependent variable. We 
included four reputation variables and two determinants concerning the personal experiences of the trustor as independent variables. Two variables per type of reputation information are added: reputation availability and reputation score. The former is a dichotomous variable indicating whether the trustee already made decisions in the relevant role ('Made trustee decision' and 'Made trustor decision') and the latter reflects the historical trust or trustworthiness rate of the partner of the trustor ('Honor rate history'and 'Place rate history'). The variables for the personal experiences of the trustor are the rate at which the trustor has experienced trust placed by his or her partner ('Experienced trustfulness') and the rate at which the trustor has experienced trustworthiness ('Experienced trustworthiness'). The models for the single-role reputation conditions (models 1 and 3 in Table 2) only include the two reputation variables for past trustworthiness behavior. The models for the mixed-role reputation conditions (models 2 and 4 in Table 2) also include the two reputation variables for past trusting behavior. The multilevel logistic regression with random intercepts for both subjects and groups did not converge for the Trust Game with single-role reputation, so instead we performed a multilevel regression with only random intercepts for subjects in that condition.

To test hypothesis $1 \mathrm{~b}$, we performed two multilevel logistic regressions on the mixed-role reputation condition only (models 5 and 6 in table 2). Game type, round number, two personal experience indicators and the four reputation variables are included as predictor variables.

To test hypotheses $2 \mathrm{a}$ and $2 \mathrm{~b}$ about the differences in trust between the four conditions, we use Wilcoxon rank-sum tests that treat each matching group as one observation to compare the trust rates between the condition. The results of these tests are reported in chapter 4.2. As a second test of the differences between the conditions, we performed a multilevel logistic regression to take care of the multi-level structure of the data and to test the interaction between game type and reputation type. We include the decision of the trustor (place trust or not) as the dependent variable and random intercepts for trustors and groups. Game type (Trust Game 
versus Lending Game) and reputation type (single-role versus mixed-role reputation) are included as independent variables, as well as the interaction between the two. Round number is included as a main effect and as an interaction with reputation condition. The results of this regression are reported in model 7 in Table 2 . The conclusions from the rank-sum tests are the same as those of the regressions.

We also performed rank-sum tests and five multilevel logistic regressions to see whether there are differences in the level of trustworthiness between conditions. In the regressions we include the decision of the trustee (honor trust or not) as the dependent variable. In each analysis, we included random intercepts for subjects and groups. The results of these regressions are in Table 3. First, we did a regression pooling all conditions (model 1 in Table 3), with game type, reputation type, the interaction between the two and round number as independent variables. The next four models (models 2 through 5) regress the decision of the trustee on the round number and four variables indicating whether that trustee made a decision as a trustee and as a trustor ('Made trustee decision' and 'Made trustor decision) and the trustee's historical trustworthiness rate and trust rate ('Honor rate history' and 'Place rate history'.

\subsection{Descriptives and results rank-sum tests}

Table 1 shows the average rates of trust, trustworthiness and the 'success rate' per condition: the fraction of interactions in which trust is placed and honored. The Wilcoxon rank-sum test shows that the trust rate is significantly higher in the Trust Game than in the Lending Game (z $=4.135, \mathrm{p}<.001)$. In the Trust Game there is no significant difference between the trust rate in the single-role reputation condition and the mixed-role reputation condition $(\mathrm{z}=.000, \mathrm{p}$ $=1.000$ ), but in the Lending Game, the trust rate is higher in the mixed-role reputation condition 
than in the single-role reputation condition $(\mathrm{z}=-2.074, \mathrm{p}=.038)$, partly confirming hypothesis $2 \mathrm{a}$ and $2 \mathrm{~b}$.

In the Trust Game, significantly more trust is honored in the single-role reputation condition than in the mixed-role reputation condition $(z=2.722, \mathrm{p}=.007)$, while in the Lending Game, the trustworthiness rate is higher in the mixed-role reputation condition than in the single-role reputation condition $(\mathrm{z}=-2.286, \mathrm{p}=.022)$. There is no overall difference in trustworthiness rate between the Trust Game and the Lending Game $(\mathrm{z}=1.360, \mathrm{p}=.174)$.

A Wilcoxon rank-sum test shows that the success rate is significantly higher in the Trust Game than in the Lending Game $(\mathrm{z}=3.891, \mathrm{p}<.001)$ and that there is no overall significant effect of reputation type $(\mathrm{z}=-0.327, \mathrm{p}=0.744)$. In the Trust Game, there is no significant difference in the success rate between the single-role reputation condition and the mixed-role reputation condition $(\mathrm{z}=1.363, \mathrm{p}=0.173)$. In the Lending Game, the success rate is higher in the mixedrole reputation condition than in the single-role reputation condition $(\mathrm{z}=-2.575, \mathrm{p}=0.010)$.

Figure 3 shows how the trustee's previous decisions and the probability that the trustor places trust in the current round are related. We hypothesized that the more a trustee has placed trust in the past, the higher the likelihood that the trustee will be trusted (H1b). The figure suggests that this is indeed the case.

Table 1: Trust and trustworthiness rate, by condition (standard deviations in parenthesis)

\begin{tabular}{|c|c|c|c|c|c|c|c|}
\hline Condition & & $\mathbf{N}$ & $\begin{array}{l}\text { Trust rate } \\
\text { (SD) }\end{array}$ & $\mathbf{N}$ & $\begin{array}{l}\text { Trustworthiness } \\
\text { rate (SD) }\end{array}$ & $\mathbf{N}$ & $\begin{array}{l}\text { Rate of both } \\
\text { combined, by } \\
\text { pair (SD) }\end{array}$ \\
\hline \multirow[t]{3}{*}{ Trust game } & Single-role & 2160 & $.217(.412)$ & 468 & $.767(.423)$ & 1080 & $.332(.471)$ \\
\hline & Mixed-role & 1944 & $.207(.406)$ & 404 & $.599(.491)$ & 972 & $.249(.250)$ \\
\hline & Total & 4104 & $.212(.409)$ & 872 & $.689(.463)$ & 2052 & $.293(.455)$ \\
\hline \multirow[t]{3}{*}{ Lending game } & Single-role & 1944 & $.056(.230)$ & 109 & $.459(.501)$ & 972 & $.051(.221)$ \\
\hline & Mixed-role & 2160 & $.100(.300)$ & 216 & $.690(.464)$ & 1080 & $.138(.345)$ \\
\hline & Total & 4104 & $.079(.270)$ & 325 & $.612(.488)$ & 2052 & $.097(.296)$ \\
\hline Total & & 8208 & $.146(.353)$ & 1197 & $.668(.471)$ & 4104 & $.195(.396)$ \\
\hline
\end{tabular}



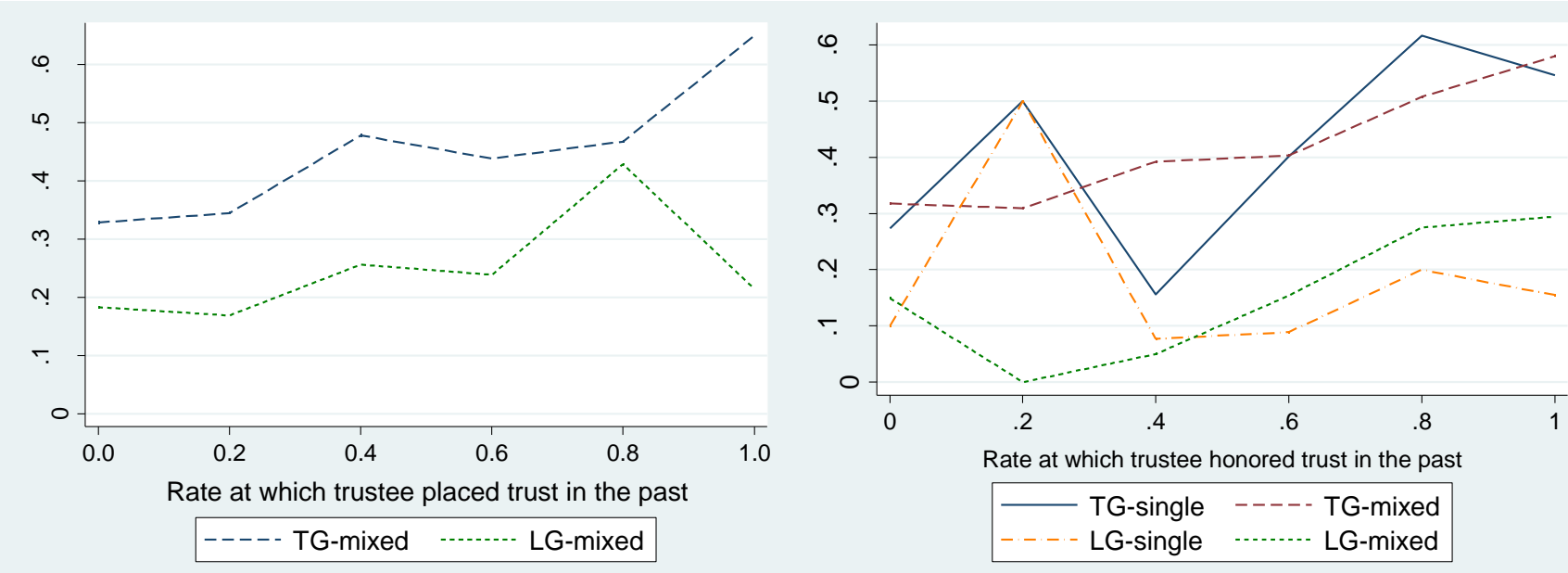

Figure 3: Relation between previous decisions made by the trustee and the probability that trust is placed by the trustor in the current round. Left panel: previous decisions made by the trustee in the trustee role (honor versus abuse) on the x-axis. Right panel: previous decisions made by the trustee in the trustor role (place versus not place trust) on the $x$-axis.

Figure 4 shows how the trust rate changes over time in the various conditions (left panel) and how the trustworthiness rate changes over time (right panel). Both panels show the "end game effect", the familiar tendency for trust placement on honoring to decrease as the known end of the session is approached.
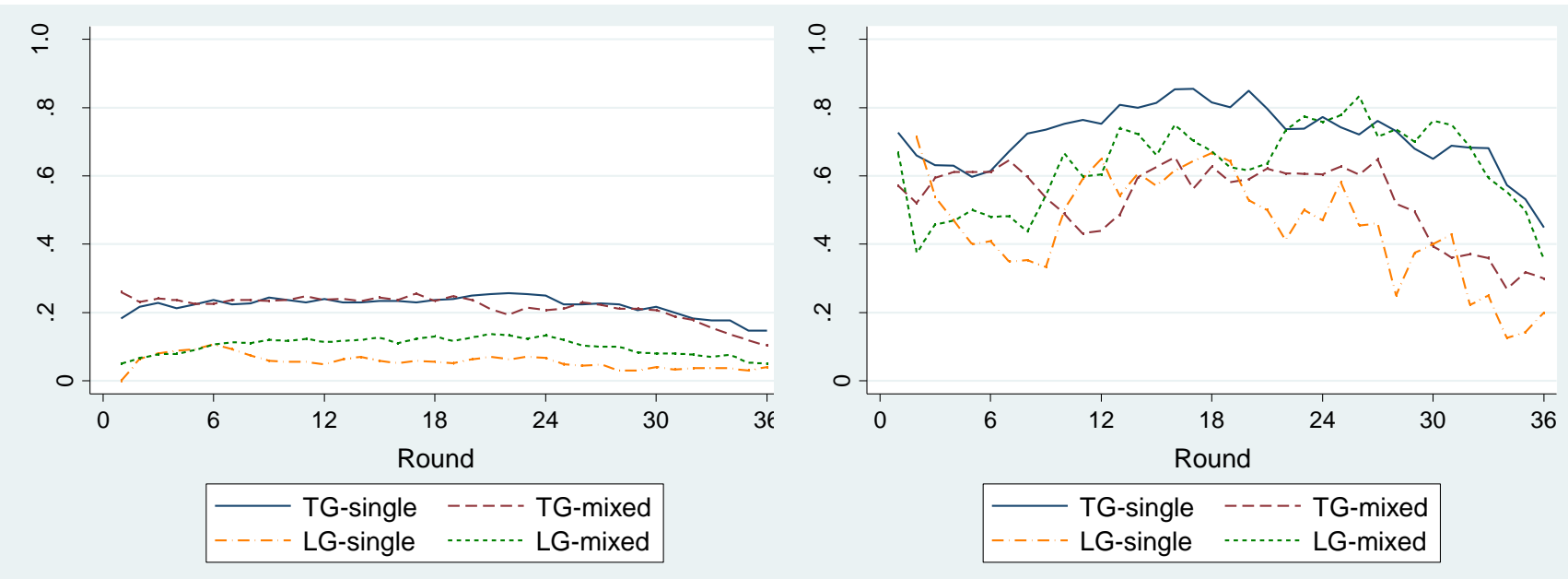

Figure 4: Left panel: probability that the trustor places trust over the rounds per condition. Right panel: probability that the trustee honors trust over the rounds per condition. Moving average over five rounds. 


\subsection{Results regressions: determinants of trust}

\subsubsection{Individual trustor decisions.}

Contrary to what we hypothesized (H1a), we find that the trustee's historical trust rate (Place rate history') does not significantly affect the probability that a trustor placed trust in the mixedrole reputation conditions if we separately look at the Trust Game and the Lending Game (models 2 and 4 in Table 2). However, these tests may lack the necessary power, because when we combine the two games in one analysis, we find that the historical trust rate significantly predicts trustor behavior (model 5 in Table 2), supporting hypothesis 1a. A 0.1 increase in the fraction of trust placed on average leads to an increase of 0.01 in the probability that the trustor places trust in both the Trust Game and the Lending Game.

The coefficients for availability of first-mover role reputation ('Made trustor decision') are not significant, also not when we combine the Trust Game and the Lending Game $(b=-0.354$, $\mathrm{z}=-1.18, \mathrm{p}=0.239$ ). This could mean that there is no difference in the probability of receiving trust between trustees who have never been in the trustor role and trustees who have been in the trustor role, but have never placed trust. However, it is only in the first six rounds of the experiment that trustees may not have played in the trustor role yet, so we cannot conclude that in all rounds of the game having no reputation and having a bad reputation have a similar effect on the probability of receiving trust.

The effect of the fraction of trust placed by the trustee on the probability that a trustor places trust is not stronger in the Lending Game than in the Trust Game ('Place rate history * LG', model 6 in Table 2), so we reject hypothesis $1 b$.

In all four conditions except the Lending Game with single-role reputation information, a trustee's historical trustworthiness rate ('Honor rate history') has a significant effect on the trustor's decision whether to place trust. Trustors more often place trust in trustees who have honored more trust in the past. If the fraction of trust honored by a trustee increases with 0.1 , 
the probability that a trustor placed trust on average increases with 0.04 and 0.03 in the Trust Game with single-role and mixed-role reputation respectively, and with 0.02 in the Lending Game with mixed-role reputation. While the coefficient of reputation score is positive, the coefficient of having a trustee reputation score ('Made trustor decision') is negative and significant in the same three conditions,. This means that trustees who have abused trust relatively often are trusted less often than trustees who have not had the chance to choose between honoring and abusing trust.

The rate at which a trustor has experienced trust ('Experienced trustfulness) does not significantly affect the probability of placing trust in any of the conditions, but the more trustworthiness the trustor has experienced ('Experienced trustworthiness), the higher the probability of placing trust. In both Trust Games the probability that a trustor places trust increases with about 0.03 with every 0.1 increase in the rate of experienced trustworthiness. In the Lending Game with single-role reputation this probability increases with 0.01 with every 0.1 increase in the rate and in the Lending Game with mixed-role reputation the probability increases with 0.03 .

\subsubsection{Overall trust rate.}

Confirming the results of the rank-sum test, the regression shows that the probability that a trustor placed trust is 0.35 higher in the Trust Game than in the Lending Game ('LG', model 7 in Table 2). and that there is no effect of type of reputation system in the Trust Game. However, the interaction between game type and reputation system type (' $L G$ * MRR') is significant, providing further support for hypothesis $2 \mathrm{~b}$. In a separate analysis for two game types, we find that after controlling for round number, in the Lending Game the probability that trust is placed is 0.10 higher in the mixed-role reputation condition than in the single-role reputation condition $(\mathrm{b}=1.129, \mathrm{z}=2.81, \mathrm{p}=0.005)$, but that the effect of reputation system type is not significant in the Trust Game $(b=-0.154, z=-0.62, p=0.537)$. 
Table 2: Determinants of trust

\begin{tabular}{|c|c|c|c|c|c|c|c|}
\hline Independent variables & $\begin{array}{l}\text { Model 1: } \\
\text { TG, SRR }\end{array}$ & $\begin{array}{l}\text { Model 2: } \\
\text { TG, MRR }\end{array}$ & $\begin{array}{l}\text { Model 3: } \\
\text { LG, SRR }\end{array}$ & $\begin{array}{l}\text { Model 4: } \\
\text { LG, MRR }\end{array}$ & $\begin{array}{l}\text { Model 5: } \\
\text { MRR }\end{array}$ & $\begin{array}{l}\text { Model 6: } \\
\text { MRR }\end{array}$ & $\begin{array}{l}\text { Model 7: } \\
\text { All } \\
\text { conditions }\end{array}$ \\
\hline Constant & $\begin{array}{l}-1.106 \\
(0.339)\end{array}$ & $\begin{array}{l}-0.652 \\
(0.417)\end{array}$ & $\begin{array}{l}-3.481 \\
(0.462)\end{array}$ & $\begin{array}{l}-2.992 \\
(0.430)\end{array}$ & $\begin{array}{l}-0.763 \\
(0.329)\end{array}$ & $\begin{array}{l}-1.533 \\
(0.363)\end{array}$ & $\begin{array}{l}0.107 \\
(0.220)\end{array}$ \\
\hline $\begin{array}{l}\text { Lending Game } \\
(\mathrm{LG}, \text { ref. cat }=\mathrm{TG})\end{array}$ & - & - & - & - & $\begin{array}{l}-1.281 * * * \\
(0.266)\end{array}$ & $\begin{array}{l}-1.186 * * * \\
(0.338)\end{array}$ & $\begin{array}{l}-2.583 * * * * \\
(0.301)\end{array}$ \\
\hline $\begin{array}{l}\text { Mixed-role reputation } \\
\text { (MRR, ref. cat. = SRR) }\end{array}$ & - & - & - & - & - & - & $\begin{array}{l}-0.085 \\
(0.304)\end{array}$ \\
\hline $\mathrm{LG} * \mathrm{MRR}$ & - & - & - & - & - & - & $\begin{array}{r}1.198^{* *} \\
(0.396)\end{array}$ \\
\hline Round number & $\begin{array}{l}-0.023 * * \\
(0.007)\end{array}$ & $\begin{array}{l}-0.034 * * * \\
(0.008)\end{array}$ & $\begin{array}{l}-0.040 * * \\
(0.013)\end{array}$ & $\begin{array}{l}-0.023^{* *} \\
(0.009)\end{array}$ & $\begin{array}{l}-0.032 * * * \\
(0.006)\end{array}$ & $\begin{array}{l}-0.031 * * * \\
(0.006)\end{array}$ & $\begin{array}{l}-0.026^{* * * *} \\
(0.006)\end{array}$ \\
\hline MRR * Round number & - & - & - & - & - & - & $\begin{array}{l}-0.005 \\
(0.008)\end{array}$ \\
\hline Made trustee decision & $\begin{array}{l}-1.108^{* * *} \\
(0.257)\end{array}$ & $\begin{array}{l}-1.207 * * * \\
(0.335)\end{array}$ & $\begin{array}{l}0.491 \\
(0.311)\end{array}$ & $\begin{array}{l}-0.785^{* *} \\
(0.300)\end{array}$ & $\begin{array}{l}-0.753^{* * *} \\
0.203\end{array}$ & $\begin{array}{l}-0.149 \\
(0.225)\end{array}$ & - \\
\hline Honor rate history & $\begin{array}{l}2.134 * * * \\
(0.244)\end{array}$ & $\begin{array}{l}1.654 * * * \\
(0.270)\end{array}$ & $\begin{array}{l}0.048 \\
(0.389)\end{array}$ & $\begin{array}{l}1.684 * * * \\
(0.311)\end{array}$ & $\begin{array}{l}1.282^{* * * *} \\
(0.183)\end{array}$ & $\begin{array}{r}0.839 * * \\
(0.266)\end{array}$ & - \\
\hline Made trustor decision & - & $\begin{array}{l}-0.194 \\
(0.442)\end{array}$ & - & $\begin{array}{l}-0.055 \\
(0.393)\end{array}$ & $\begin{array}{l}-0.354 \\
(0.300)\end{array}$ & $\begin{array}{l}0.298 \\
(0.364)\end{array}$ & - \\
\hline Place rate history & - & $\begin{array}{l}0.534 \\
(0.327)\end{array}$ & - & $\begin{array}{l}0.766 \\
(0.406)\end{array}$ & $\begin{array}{l}0.668^{* *} \\
(0.247)\end{array}$ & $\begin{array}{l}-0.429 \\
(0.514)\end{array}$ & - \\
\hline $\begin{array}{l}\text { Experienced } \\
\text { trustfulness }\end{array}$ & $\begin{array}{l}-2.288 \\
(2.476)\end{array}$ & $\begin{array}{l}2.225 \\
(2.638)\end{array}$ & $\begin{array}{l}-1.599 \\
(1.031)\end{array}$ & $\begin{array}{l}1.031 \\
(0.922)\end{array}$ & $\begin{array}{l}-1.514 \\
(1.279)\end{array}$ & $\begin{array}{l}-1.752 \\
(1.408)\end{array}$ & - \\
\hline $\begin{array}{l}\text { Experienced } \\
\text { trustworthiness }\end{array}$ & $\begin{array}{l}1.449 * * * \\
(0.290)\end{array}$ & $\begin{array}{l}1.903 * * * \\
(0.355)\end{array}$ & $\begin{array}{l}3.410 * * * \\
(0.566)\end{array}$ & $\begin{array}{l}2.457 * * * \\
(0.329)\end{array}$ & $\begin{array}{l}2.122 * * * \\
(0.235)\end{array}$ & $\begin{array}{l}2.564 * * * \\
(0.252)\end{array}$ & - \\
\hline Place rate history $*$ LG & - & - & - & - & - & $\begin{array}{l}-1.039 \\
(0.665)\end{array}$ & - \\
\hline $\mathrm{N}$ & 1080 & 972 & 972 & 1080 & 2052 & 2052 & 4104 \\
\hline LL & -620.895 & -513.134 & -241.063 & -419.861 & -955.633 & -970.141 & -1995.384 \\
\hline
\end{tabular}

* indicates significance at $p=.05$ (two-tailed tests)

$* *$ indicates significance at $p=.01$ ( two-tailed tests)

$* * *$ indicates significance at $p=.001$ (two-tailed tests)

Standard errors are in parentheses. TG refers to Trust Game, LG refers to Lending Game. SRR refers to singlerole reputation system and MRR to mixed-role reputation system. Made trustee decision (Made trustor decision) indicates whether the trustee has made a decision in the trustee (trustor) role yet. Honor rate history (Place rate history) indicates the rate at which the trustee has honored (placed) trust in the past. Experienced trustfulness (Experiences trustworthiness) is the rate at which the trustor experienced trust placed (honored). 


\subsection{Results regressions: determinants of trustworthiness}

\subsubsection{Individual trustee decision.}

In later rounds trustees become less and less likely to honor trust, although this effect is only significant in the Trust Game and not in the Lending Game. On average, the probability that a trustee honors trust decreases with 0.07 per ten rounds. We find that a trustee's previous decisions in the trustee role ('Honor rate history') predict the trustee's honoring decision in both Trust Games and in the Lending Game in the single-role reputation condition. With every 0.1 increase in the trustee's historical trustworthiness rate, the probability that a trustee honors trust increases with 0.03 and 0.04 in the Trust Game with single-role reputation and mixed-role reputation respectively. In the Lending Game with single-role reputation, the probability that a trustee honors trust increases with 0.05 with every 0.1 increase in the trustee's historical trustworthiness rate. The trustee's previous decisions in the trustor role ('Place rate history') have a significant and positive effect on the probability that a trustee will honor trust in both games with mixed-role reputation. With every 0.1 increase in the trustee's historical trust rate, the probability that that trustee honors trust increases with 0.04 in both games with mixed-role reputation. In the games with single-role reputation the trustee's historical trust rate is not a significant predictor of the trustee's decision.

\subsubsection{Overall trustworthiness rate.}

Model 1 in Table 3 shows that more trust is honored in the Trust Game than in the Lending Game ('LG') in the single-role reputation condition. On average, the probability that a trustee honors trust is 0.09 higher in the Trust Game than in the Lending Game with single-role reputation. By comparison, in the mixed-role reputation condition we find that the trustworthiness rate does not significantly differ between the Trust Game and the Lending Game $(b=.388, z=0.95, p=.341)$. 
Confirming the results of the rank-sum test, we find that the interaction between game type and reputation system type (' $L G$ * MRR') is significant: in the Trust Game the probability that trust is honored is 0.17 higher in the single-role reputation condition than in the mixed-role reputation condition, but in the Lending Game the probability that trust is honored is 0.14 higher in the mixed-role reputation condition $(b=1.062, z=1.97, p=0.049)$.

Table 3: Determinants of trustworthiness in the different conditions

\begin{tabular}{llllll}
\hline Independent variables & $\begin{array}{l}\text { Model 1: All } \\
\text { conditions }\end{array}$ & $\begin{array}{l}\text { Model 2: TG, } \\
\text { SRR }\end{array}$ & $\begin{array}{l}\text { Model 3: TG, } \\
\text { MRR }\end{array}$ & $\begin{array}{l}\text { Model 4: LG, } \\
\text { SRR }\end{array}$ & $\begin{array}{l}\text { Model 5: LG, } \\
\text { MRR }\end{array}$ \\
\hline Constant & 1.981 & 1.825 & 0.464 & 0.099 & 2.500 \\
& $(0.328)$ & $(0.573)$ & $(0.530)$ & $(1.431)$ & $(0.967)$ \\
Lending Game (LG, ref. & $-1.661^{* *}$ & - & - & - & - \\
cat. = TG) & $(0.481)$ & & & & \\
Mixed-role reputation & $-1.060^{*}$ & - & - & - & - \\
(MRR, ref. cat. SRR) & $(0.429)$ & & & & \\
LG* MRR & $2.048^{* *}$ & - & - & - & - \\
& $(0.666)$ & & & & \\
Round number & $-0.048^{* * *}$ & $-0.031^{* *}$ & $-0.050^{* * *}$ & -0.044 & -0.004 \\
& $(0.009)$ & $(0.012)$ & $(0.014)$ & $(-0.029)$ & $(0.026)$ \\
Made trustee decision & - & 0.049 & $-1.058^{*}$ & -1.668 & $1.625^{*}$ \\
& & $(0.426)$ & $(0.459)$ & $(0.854)$ & $(0.783)$ \\
Honor rate history & - & $1.766^{* * *}$ & $1.998^{* * *}$ & $3.243 *$ & 0.648 \\
& & $(0.392)$ & $(0.574)$ & $(1.131)$ & $(1.007)$ \\
Made trustor decision & - & $-1.400^{*}$ & $-0.180^{* * *}$ & -0.173 & $-3.890^{* * *}$ \\
& & $(0.598)$ & $(0.578)$ & $(1.499)$ & $(0.904)$ \\
Place rate history & - & 0.299 & $1.924^{* *}$ & 3.822 & $2.639 *$ \\
& & $(0.430)$ & $(0.547)$ & $(3.269)$ & $(1.213)$ \\
$\mathrm{N}$ & 1197 & 468 & 404 & 109 & 216 \\
LL & -649.192 & -233.104 & -219.668 & -57.022 & -100.110 \\
\hline
\end{tabular}

* indicates significance at $p=.05$ (two-tailed tests)

$* *$ indicates significance at $p=.01$ ( two-tailed tests)

$* * *$ indicates significance at $p=.001$ (two-tailed tests)

Standard errors are in parentheses. TG refers to Trust Game, LG refers to Lending Game. SRR refers to singlerole reputation system and MRR to mixed-role reputation system. Made trustee decision (Made trustor decision) indicates whether the trustee has made a decision in the trustee (trustor) role yet. Honor rate history (Place rate history) indicates the rate at which the trustee has honored (placed) trust in the past (Made trustor decision) indicates whether the trustee has made a decision in the trustee (trustor) role yet. Honor rate history (Place rate history) indicates the rate at which the trustee has honored (placed) trust in the past 


\section{DISCUSSION}

The focus of this paper has been on the increasingly common scenario in which individuals are sometimes provider and sometimes user of a borrowed good (e.g. eBay, Couchsurfing, Kickstarter). We have argued that in these settings, a new form of reputation building emerges: Individuals lend out valuable property for free to unknown others, risking exploitation, in the expectation that when they themselves call on help that requires another person's willingness to trust them, they will more likely receive it themselves. We theorized that systems in these mixed-role settings increase levels of trust by broadcasting these generous acts publicly. However, we expected this reputational mechanism to be less effective in settings where lenders charge for their services, as temporary provision of a good is here no longer an unambiguously generous act.

This argument was largely supported in a laboratory study. We found that, indeed, mixedrole reputation systems increased trust levels, and only for scenarios of lending, not letting. However, the experiment also posed a puzzle. On the one hand, we found some evidence that users who have placed more trust in the past are trusted more often, supporting the theory that providers use the extra information to assess the trustworthiness of the users (learning) and to reward and punish them for their behavior in the past (indirect reciprocity). At the same time, the extent to which providers base their decisions on the information about the user was found limited. While this limited usage of the extra information may be in line with earlier research that suggests that the presence of incentives for prosocial behavior (control) breaks down the relation between prosocial behavior and altruism (Charness et al., 2011; Simpson \& Willer, 2008), it raises the question why trustors would believe that placing trust will be rewarded in the future when that is not actually the case. We speculate that the answer might have to do with the overall trust levels in our experiment, which were low compared to other experiments 
on the Trust Game and the Helping Game with reputation systems (Boero et al., 2009; Bolton et al., 2005; Buskens et al., 2010; Charness et al., 2011; Seinen \& Schram, 2006).

To see how low trust levels might play a role, considers that Simpson and Willer (2008) found that altruists' behavior tends to be more prosocial in games like the ones we studied. This suggests that the subjects in our experiment are relatively egoistic. The same study also shows that altruists respond differently to the presence of reputational incentives than egoists. Whereas altruists tend to reciprocate other people's behavior regardless of the presence of reputational incentives, egoists discount prosociality of others more when it occurs in the presence of reputational incentives (Simpson \& Willer, 2008).

Two possible reasons for this difference are that altruists and egoists project their own behavioral propensities onto others and egoists are simply more attentive to reputational cues. Even though the trust rate suggest that the participants were relatively egoistic compared to similar experiments, the subjects did not have access to this meta information during the game, and may therefore have assumed that the participant pool was more altruistic, and thus more reciprocal, than it actually was. This would explain why providers in free exchange may still have held the belief that their behavior in the provider role would be reciprocated, even though the extent to which this actually happened was limited.

Interestingly, we found that not only trust levels were higher under mixed-role than singlerole reputation conditions, but levels at which trust was honored were also higher. We offer three possible explanations for these additional beneficial effects of mixed-role reputation systems. First, providers may have made use of the information about a user's history as past provider, which is a strong predictor of the user's behavior in the current role: users who have placed more trust in the past are more likely to honor trust in the current round. By using this information, providers may thus have improved their assessment of the trustworthiness of the users they encountered, leading to more trust being placed in trustworthy individuals. Secondly, 
the increased trust rate may have made it more worthwhile to invest in a reputation. The more frequently trust is placed, the larger the chance that a user with a good reputation receives trust, so the more it pays off to have a good reputation. Lastly, because placing trust can be considered an altruistic act in free exchange, users may have directly reciprocated trustful providers by honoring trust to reward them for their generosity. These findings stand in stark contrast to what we found for paid service provision scenarios, where trust was honored less so under a mixedrole reputation regime than in a single-role reputation system.

Altogether, these findings suggest that in modern, Internet-enabled marketplaces, reputation systems allow individuals to not only develop a classic reputation for someone who can be trusted, but also to become known as someone who has paid their dues to the community, and therefore deserves to be trusted. 


\section{NOTES}

${ }^{1}$ To facilitate the distinction between trustors and trustees, we refer to the trustors with female pronouns and to the trustees with male pronouns.

${ }^{2}$ We further assume that $\mathrm{P}_{1}+\mathrm{P}_{2}>\mathrm{S}_{1}+\mathrm{T}_{2}$, which avoids that alternating between being abused and abusing trust results in a higher payoff than not placing or receiving trust at all. Namely, it is implausible that the gains from abusing someone outweigh the material loss and immaterial harm suffered when abused by someone else.

${ }^{3}$ Most platforms for online exchange provide insurance that covers damage that can be proved to be caused by the user of the good. However, when the cause of the damage is unclear (e.g. in case of a small scratch on a car) or when it is hard to immediately detect the damage (e.g. damage to the gears or breaks of a car due to wear and tear) or when it is unclear who is responsible for the repair costs, insurances may not cover the damage and trust plays a role. Then, even with insurance in place, the trust game would still accurately represent material incentives on paid platforms with single-role reputation systems.

${ }^{4}$ In many real-life situations, provision of reviews is a social dilemma in itself, because review-writers do not benefit materially from writing the review, while everybody can access them (Diekmann et al., 2014). In the current paper we abstract away from this second dilemma, assuming that reputation information is provided automatically and without costs. ${ }^{5}$ Online interactions on two-sided markets are often followed by offline interactions which in some cases induce additional (non-material) costs and benefits and informal gift exchange. For exchange, for Couchsurfing guests it is common practice to bring a small gift for the host and to spend some time together. However, the extent to which provider and consumer spend time together differs to a large extent between platforms and is decreasing with technological advantages (e.g. smart locks), we focus on the material costs and benefits that are mediated by the platform. 
${ }^{6}$ Lotteries at the beginning of each round determined which subjects in a matching group were to play in the role of trustor. The probability that a subject's lot was drawn decreased with the number of times that subject acted in the trustor role in previous rounds in the same block and increased with the number of times the other subjects acted in the trustor role in the block. 


\section{REFERENCES}

Ba, S., \& Pavlou, P. A. (2002). Evidence of the Effect of Trust Building Technology in Electronic Markets: Price Premiums and Buyer Behavior. MIS Quarterly, 26(3), 243.

Balliet, D., Mulder, L. B., \& Van Lange, P. A. M. (2011). Reward, punishment, and cooperation: A meta-analysis. Psychological Bulletin, 137(4), 594-615.

Benard, S. (2013). Reputation systems, aggression, and deterrence in social interaction. Social Science Research, 42(1), 230-245.

Boero, R., Bravo, G., Castellani, M., \& Squazzoni, F. (2009). Reputational cues in repeated trust games. The Journal of Socio-Economics, 38(6), 871-877.

Bolton, G. E., Katok, E., \& Ockenfels, A. (2004). How Effective Are Electronic Reputation Mechanisms? An Experimental Investigation. Management Science, 50(11), 1587-1602.

Bolton, G. E., Katok, E., \& Ockenfels, A. (2005). Cooperation among strangers with limited information about reputation. Journal of Public Economics, 89(8), 1457-1468.

Buskens, V. (2003). Trust in triads: Effects of exit, control, and learning. Games and Economic Behavior, 42(2), 235-252.

Buskens, V., \& Raub, W. (2002). Embedded trust: Control and learning. In S. R. Thye \& E. J. Lawler (Eds.), Group Cohesion, Trust and Solidarity (19th ed., pp. 167-202). Amsterdam: Elsevier Science.

Buskens, V., Raub, W., \& van der Veer, J. (2010). Trust in triads: An experimental study. Social Networks, 32(4), 301-312.

Buskens, V., \& Weesie, J. (2000). An experiment on the effects of embeddedness in trust situations: Buying a used car. Rationality and Society, 12(2), 227-253.

Cabral, L. L., Hortacsu, A., \& Hortaçsu, A. (2010). The dynamics of seller reputation: Evidence from eBay. The Journal of Industrial Economics, 58(1), 54-78.

Charness, G., Du, N., \& Yang, C.-L. (2011). Trust and trustworthiness reputations in an 
investment game. Games and Economic Behavior, 72(2), 361-375.

Chaudhuri, A., \& Gangadharan, L. (2007). An Experimental Analysis of Trust and Trustworthiness. Southern Economic Journal, 73(4), 959-985.

Cheshire, C. (2007). Selective Incentives and Generalized Information Exchange. Social Psychology Quarterly, 70(1), 82-100.

Coleman, J. S. (1990). Foundations of Social Theory. Cambridge: MA: Belknap.

Cook, K. S. (2005). Networks, Norms, and Trust: The Social Psychology of Social Capital* 2004 Cooley Mead Award Address. Social Psychology Quarterly, 68(1), 4-14.

Cook, K. S., Hardin, R., \& Levi, M. (2005). Cooperation Without Trust? New York: Russell Sage Found.

Cova, B., Dalli, D., \& Zwick, D. (2011). Critical perspectives on consumers' role as "producers": Broadening the debate on value co-creation in marketing processes. Marketing Theory, 11(3), 231-241.

Dasgupta, P. (1988). Trust as a Commodity. In D. Gambetta (Ed.), Trust: Making an Breaking Cooperative Relations (pp. 49-72). Cornwall: Basil Blackwell.

Dewally, M., \& Ederington, L. (2006). Reputation, Certification, Warranties, and Information as Remedies for Seller-Buyer Information Asymmetries: Lessons from the Online Comic Book Market. Source: The Journal of Business, 79(2), 693-729.

Dewan, S., Hsu, V., Dewanw, S., Hsuz, V., \& Rogers, M. (2004). Adverse Selection in Electronic Markets: Evidence from online stamp auctions. The Journal of Industrial Economics, 52(4), 497-516.

Diekmann, A., Jann, B., Przepiorka, W., \& Wehrli, S. (2014). Reputation Formation and the Evolution of Cooperation in Anonymous Online Markets. American Sociological Review, 79(1), 65-85.

Duffy, J., Xie, H., \& Lee, Y.-J. (2013). Social norms, information, and trust among strangers: 
theory and evidence. Economic Theory, 52(2), 669-708.

Elfenbein, D. W., Fisman, R., \& Mcmanus, B. (2012). Charity as a substitute for reputation: Evidence from an online marketplace. Review of Economic Studies, 79(4), 1441-1468. Engelmann, D., \& Fischbacher, U. (2009). Indirect reciprocity and strategic reputation building in an experimental helping game. Games and Economic Behavior, 67(2), 399407.

Fehr, E., \& Gächter, S. (2000). Cooperation and punishment in public goods experiments. American Economic Review, 90(4), 980-994.

Fehrler, S., \& Przepiorka, W. (2013). Charitable giving as a signal of trustworthiness: Disentangling the signaling benefits of altruistic acts. Evolution and Human Behavior, 34(2), 139-145.

Fischbacher, U. (2007). z-Tree: Zurich toolbox for ready-made economic experiments. Experimental Economics, 10(2), 171-178.

Geiger, A. (2015). Thank Me For Hosting: the Role of Reciprocity in Sharing. Advances in Consumer Research, 43, 534-535.

Geiger, A., \& Germelmann, C. C. (2015). Reciprocal Couchsurfing Versus Sharing's NonReciprocity Principle. In Proceedings of the 44th EMAC Conference.

Greiner, B. (2015). Subject Pool Recruitment Procedures: Organizing Experiments with ORSEE. Journal of the Economic Science Association, 1(1), 114-12.

Grybaite, V., \& Stankevičienė, J. (2016). Motives for participation in the sharing economy evidence from Lithuania. Ekonomia i Zarzadzanie, 8(4).

Hamari, J., Sjöklint, M., \& Ukkonen, A. (2015). The Sharing Economy: Why People Participate in Collaborative Consumption. Journal of the Association for Information Science and Technology, 67(9), 2047-2059.

Hars, A., \& Ou, S. (2002). Working for Free? Motivations for Participating in Open-Source 
Projects. International Journal of Electronic Commerce, 6(3), 25-39.

Kollock, P. (1999). The Production of Trust in Online Markets. Advances in Group Processes, 16, 99-123.

Kreps, D. M. (1996). Corporate culture and economic theory. In J. Alt \& K. Shepsle (Eds.), Firms, Organizations and Contracts (pp. 221-175). Oxford: Oxford University Press.

Kroher, M., \& Wolbring, T. (2015). Social control, social learning, and cheating: Evidence from lab and online experiments on dishonesty. Social Science Research, 53, 311-324. Kuwabara, K. (2015). Do Reputation Systems Undermine Trust? Divergent Effects of Enforcement Type on Generalized Trust and Trustworthiness. American Journal of Sociology, 120(5), 1390-1428.

Kuwabara, K., \& Yu, S. (2017). Costly Punishment Increases Prosocial Punishment by Designated Punishers: Power and Legitimacy in Public Goods Games. Social Psychology Quarterly, 80(2), 174-193.

Lauterbach, D., Truong, H., Shah, T., \& Adamic, L. (2009). Surfing a web of trust: Reputation and reciprocity on Couchsurfing.com. In 2009 International Conference on Computational Science and Engineering (Vol. 4, pp. 346-353).

Macy, M. W., \& Skvoretz, J. (1998). The Evolution of Trust and Cooperation between Strangers: A Computational Model. American Sociological Review, 63(5), 638.

Malinowski, B. (1922). Malinowski, Bronislaw. Argonauts of the Western Pacific: An account of native enterprise and adventure in the archipelagoes of Melanesian New Guinea. London: Routlegde \& Sons.

Molm, L. D. (2010). The structure of reciprocity. Social Psychology Quarterly, 73(2), 119131.

Molm, L. D., Schaefer, D. R., \& Collett, J. L. (2007). The Value of Reciprocity. Social Psychology Quarterly, 70(2), 199-217. 
Molm, L. D., Schaefer, D. R., \& Collett, J. L. (2009). Fragile and Resilient Trust: Risk and Uncertainty in Negotiated and Reciprocal Exchange. Sociological Theory, 27(1), 1-32.

Norbutas, L., \& Corten, R. (2018). Sustainability of generalized exchange in the sharing economy: the case of the "freecycling" Facebook groups. International Journal of the Commons, 12(1), 111-133.

Parigi, P., Santana, J. J., \& Cook, K. S. (2017). Online Field Experiments: Studying Social Interactions in Context. Social Psychology Quarterly, 80(1), 1-19.

Quora. (2016). CouchSurfing. Retrieved December 15, 2016, from https://www.quora.com/As-a-couchsurfing-host-I-always-end-up-out-of-pocket-becausesurfers-either-have-to-be-reminded-to-pay-for-their-own-food-or-at-least-chip-in-for-itIs-anyone-else-finding-the-same

Reddit. (2015). Couchsurfing. Retrieved December 15, 2016, from https://www.reddit.com/r/couchsurfing/comments/3dlfqi/why_is_it_so_hard_for_guys_t o_find_a_host/

Resnick, P., Kuwabara, K., Zeckhauser, R., \& Friedman, E. (2000). Reputation systems. Communications of the ACM, 43(12), 45-48.

Resnick, P., Zeckhauser, R., Swanson, J., \& Lockwood, K. (2006). The value of reputation on eBay: A controlled experiment. Experimental Economics, 9(2), 79-101.

Ritzer, G., \& Jurgenson, N. (2010). Production, Consumption, Prosumption: The nature of capitalism in the age of the digital "prosumer." Journal of Consumer Culture, 10(1), 1336.

Robbins, B. G. (2016). Probing the Links Between Trustworthiness, Trust, and Emotion: Evidence From Four Survey Experiments. Social Psychology Quarterly, 79(3), 284-308. Rooks, G., Raub, W., \& Tazelaar, F. (2006). Ex post problems in buyer-supplier transactions: Effects of transaction characteristics, social embeddedness, and contractual governance. 
Journal of Management and Governance, 10(3), 239-276.

Seinen, I., \& Schram, A. (2006). Social status and group norms: Indirect reciprocity in a repeated helping experiment. European Economic Review, 50(3), 581-602.

Simpson, B., \& Willer, R. (2008). Altruism and Indirect Reciprocity: The Interaction of Person and Situation in Prosocial Behavior. Social Psychology Quarterly, 71(1), 37-52.

Snijders, C., \& Zijdeman, R. (2004). Reputation and internet auctions: eBay and beyond. Analyse \& Kritik.

Stanca, L. (2009). Measuring indirect reciprocity: Whose back do we scratch? Journal of Economic Psychology, 30(2), 190-202.

Takahashi, N. (2000). The Emergence of Generalized Exchange. American Journal of Sociology, 105(4), 1105-1134.

Takahashi, N., \& Mashima, R. (2003). The Emergence of Indirect Reciprocity: Is the standing strategy the answer? Working Paper Series. Center for the Study of Cultural and Ecological Foundations of the Mind, Hokkaido University, Japan., 29.

Tsvetkova, M., \& Macy, M. W. (2014). The social contagion of generosity. PLoS ONE, 9(2), e87275.

Weigelt, K., \& Camerer, C. (1988). Reputation and corporate strategy: A review of recent theory and applications. Strategic Management Journal, 9(5), 443-454.

Yamagishi, T., \& Cook, K. S. (1993). Generalized Exchange and Social Dilemmas. Social Psychology Quarterly, 56(4), 235. 


\section{APPENDIX A - INSTRUCTIONS FOR PARTICIPANTS}

Differences between the conditions are marked with an indented, underlined reference to the relevant conditions.

Welcome and thank you for coming!

Please read the following instructions carefully. Please do not communicate with other participants. Turn off your phone and put it away. Also, you may not use any function of the computer that is not necessary for carrying out the experiment. Thank you very much for your participation. If at any point you have questions, raise your hand and we will assist you.

In this experiment you can earn money by scoring 'points' for certain decisions. These points will at the end of the experiment be exchanged for money. The number of points you score depends on your decisions and on the decisions of others. For every 100 points you score in the experiment, you will receive $€ 0.60$ (total amount rounded to $€ 0.50$ ).

These instructions are the same for all participants in the room. All of the payments are real and all participants are present in this room. All information that you read about in this study is truthful and real. No other participant will be able to link your decisions to your identity or get to know your name or earnings. After everybody has read the instructions, there will be a quiz in which you can make sure that you understand everything correctly. Then, we turn to the next stage during which you can score points by playing several rounds of a game. At the end of the session you will be asked to answer a short survey.

\section{Description of the game}

The game proceeds in rounds and is played in groups of 6,8 or 10 participants (depending on the total number of participants in the session). At the beginning of each round, half of the participants in your group is assigned to role A and half of the participants is assigned to role B. Then, you are randomly matched with another participant in the other role (if you are 
assigned to role A, you are matched to a participant with role B and vice versa). In case you are by chance matched multiple times with the same other participant, neither you nor the other participant knows this.

Figure 1 shows the basic interaction situation. Player A starts and chooses between RIGHT and DOWN. If player A chooses RIGHT, player A and player B both receive 40 points. If player A chooses DOWN, player B has to make a decision. If player B also chooses DOWN,

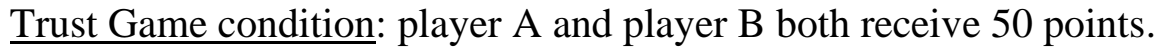

Lending Game condition: player A receives 36 points and player B receives 50 points. If player B chooses RIGHT, player A receives 0 points and player B receives 70 points.

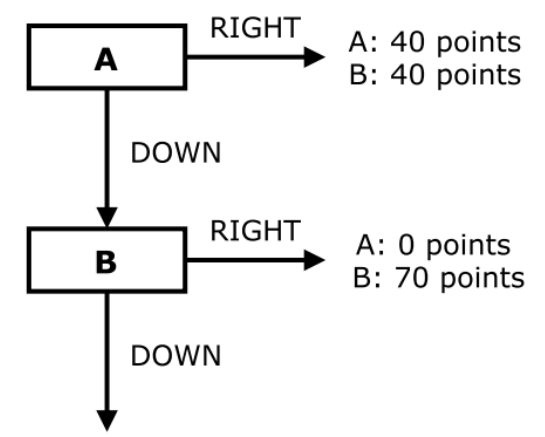

$\begin{array}{ll} & \text { A: } 50 \text { points } \\ \text { Trust Game: } & \text { B: } 50 \text { points }\end{array}$

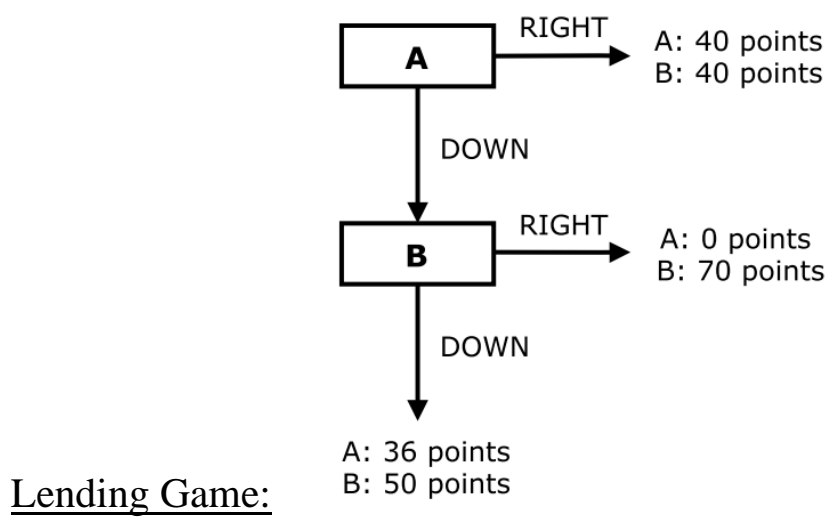

\section{Figure 1}




\section{The duration of the game}

The game lasts for 36 rounds. You will be assigned to role A 18 times and to role B also 18 times. However, your role may change every round and the order in which you are playing in role $\mathrm{A}$ and role $\mathrm{B}$ is determined randomly.

\section{The computer interface}

Figure 2 to 4 show examples of the computer interface. On top of the screen you can see the number of the current round, your role in this round and the number of times you have already played in each of the roles. At the bottom of the screen you can see the outcomes of previous rounds. Use the scroll bar to scroll back to earlier rounds.

Figure 2 shows the decision screen of player A.

Single-role reputation condition: At the beginning of every round, all players A are informed about the previous decisions in role B of the player B they are matched with.

Mixed-role reputation condition: At the beginning of every round, all players A are informed about the previous decisions in role A and B of the player B they are matched with.

This information is shown in the left panel.

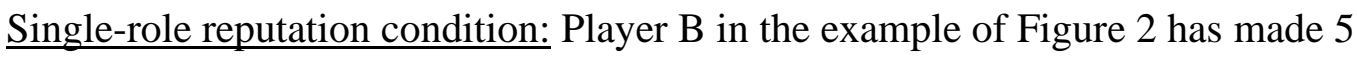
decisions in role B and chose 2 times RIGHT and 3 times DOWN in this role. Mixed-role reputation condition: Player B in the example of Figure 2 has made 3 decisions in role A and chose 2 times RIGHT and 1 times DOWN in this role. Player B also chose 2 times RIGHT and 1 time DOWN in role B in the example.

In the right panel you can indicate your decision for RIGHT or DOWN. Make your decision by clicking with your mouse on the corresponding arrow. When you click on one of the 
arrows, the arrow will turn bold and blue and an 'OK'-button appears. Please click the 'OK'button to proceed.

Figure 3 shows an example of the interface of the decision screen of player B. You will only see this screen if the player in role A that you are matched with chooses DOWN. You can decide between RIGHT and DOWN by clicking with your mouse on the corresponding arrow. When you click on one of the arrows, the arrow will turn bold and blue and an 'OK'-button appears. Please click the 'OK'-button to proceed.

After every round, you can see the decisions and number of points scored by you and by the other participant in the current round. The other participant can also see your decision and the number of points scored by you in the current round. You also see the sum of your points in all rounds. You also see the sum of your points in all rounds. Figure 4 shows an example of this screen. Please click the 'OK'-button to proceed to the next round.

\section{Quiz}

You have finished reading the instructions. Feel free to have another look at the parts you found difficult to understand. Please turn to the computer and answer a few questions that help you evaluate your understanding of the game. You cannot score (or lose) points by answering these questions. The goal is only to make sure that you understand everything correctly. If you have questions, please raise your hand. Otherwise, turn to the computer and click "OK. 